BMJ Open

Diabetes

Research

\& Care

\title{
Secondary metformin monotherapy failure in individuals with type 2 diabetes mellitus
}

\author{
Tracey Weiss (D) , ${ }^{1}$ Kristy Iglay, ${ }^{1}$ Tania Gulati, ${ }^{2}$ Swapnil Rajpathak (D) , \\ Lingfeng Yang, ${ }^{1}$ Lawrence Blonde ${ }^{3}$
}

To cite: Weiss T, Iglay K, Gulati T, et al. Secondary metformin monotherapy failure in individuals with type 2 diabetes mellitus. BMJ Open Diab Res Care 2021;9:e002127. doi:10.1136/ bmjdrc-2021-002127

- Supplemental material is published online only. To view, please visit the journal online (http://dx.doi.org/10.1136/ bmjdrc-2021-002127).

Received 11 January 2021 Accepted 9 May 2021
Check for updates

\section{(c) Author(s) (or their} employer(s)) 2021. Re-use permitted under CC BY-NC. No commercial re-use. See rights and permissions. Published by BMJ.

${ }^{1}$ Center for Observational and Real-World Evidence, Merck \& Co., Inc, Kenilworth, New Jersey, USA

${ }^{2}$ Complete HEOR Solutions, North Wales, Pennsylvania, USA ${ }^{3}$ Ochsner Diabetes Clinical Research Unit, Ochsner Health System, New Orleans, Louisiana, USA

Correspondence to Dr Tracey Weiss; tracey.weiss@merck.com

\section{ABSTRACT}

Introduction To assess secondary metformin monotherapy (MM) failure in a real-world type 2 diabetes mellitus (T2DM) cohort.

Research design and methods Using the IQVIA Electronic Medical Record (formerly GE Centricity) database, adults with T2DM who initiated MM between January 1, 2012 and June 30, 2016 and achieved glycemic control (hemoglobin A1c (HbA1c) < $\%$ (53 mmol/ mol); index date) were analyzed. Secondary MM failure was defined in two ways: loss of glycemic control (HbA1c $\geq 7 \%(53 \mathrm{mmol} / \mathrm{mol})$ ) and treatment change (addition or switch of antihyperglycemic agent). Multivariable logistic regression models assessed the association between secondary MM failure and sociodemographic and clinical factors.

Results The analysis included 4775 patients initiating MM. $32.9 \%$ and $19.2 \%$ experienced secondary MM failure at 24 months measured as loss of glycemic control and treatment change, respectively. Multivariable logistic regression found that women $(\mathrm{OR}=1.3,95 \% \mathrm{Cl} 1.1$ to 1.5$)$ compared with men, lower Charlson Comorbidity Index (CCI) (OR=0.89, $95 \% \mathrm{Cl} 0.86$ to 0.93$)$, and lower baseline HbA1C (OR $=0.93,95 \% \mathrm{Cl} 0.88$ to 0.98 ) were associated with increased likelihood of loss of glycemic control. Lower $\mathrm{CCl}$ was associated with increased likelihood of treatment change ( $\mathrm{OR}=0.78,95 \% \mathrm{Cl} 0.75$ to 0.82 ).

Conclusions The observed frequency of secondary MM failure underscores the importance of the American Diabetes Association's recommendation for glycemic monitoring of at least every 6 months so that timely therapeutic adjustments can be made.

\section{INTRODUCTION}

Type 2 diabetes mellitus (T2DM) is a chronic and progressive disease characterized by elevated blood glucose levels. Estimates from national studies and surveillance registries in the USA estimate the prevalence of diabetes among adults age 18 and older is $13 \%$, of which $21.4 \%$ are undiagnosed. ${ }^{1}$ For most patients, the American Diabetes Association (ADA) standards of care state that 'An A1C goal for many non-pregnant adults of $<7 \%$ (53 $\mathrm{mmol} / \mathrm{mol}$ ) is appropriate', although less stringent targets may be appropriate for some patients. ${ }^{2}$ Half of patients with T2DM

\section{Significance of this study}

What is already known about this subject?

- In the double-blind, randomized clinical trial ADOPT (A Diabetes Outcome Progression), in 4360 patients with type 2 diabetes mellitus, the cumulative prevalence of metformin monotherapy (MM) failure after 5 years of follow-up was $21 \%$.

- Although a few studies have characterized secondary MM failure in the real world, they used data from a single healthcare system and thus their generalizability to the broader US population is limited.

What are the new findings?

- In a broad sample of US patients, nearly one-third $(32.9 \%)$ of patients experienced secondary MM failure, defined as loss of glycemic control (hemoglobin A1c (HbA1c) $\geq 7 \%(53 \mathrm{mmol} / \mathrm{mol}))$ and nearly one-fifth $(19.2 \%)$ of patients experienced secondary MM failure, defined as treatment change, after 24 months. This indicates that a substantial proportion of individuals with type 2 diabetes who achieve glycemic targets on MM go on to lose glycemic control or change therapy in a relatively short period of time.

- Factors associated with increased risk of progression to $\mathrm{HbA} 1 \mathrm{C} \geq 7 \%(53 \mathrm{mmol} / \mathrm{mol})$ were being a woman, having lower baseline $\mathrm{HbA1C}$, and having lower Charlson Comorbidity Index (CCI). Only lower $\mathrm{CCl}$ was found to be associated with increased risk of treatment change.

How might these results change the focus of research or clinical practice?

- The observed frequency of secondary MM failure underscores the importance of the American Diabetes Association's recommendation for glycemic monitoring of at least every 6 months so that timely therapeutic adjustments can be made.

have suboptimal glycemic control. ${ }^{34}$ Optimal glycemic control reduces the risk of hypoglycemia, cardiovascular disease, kidney disease, liver disease, obesity, and other microvascular complications.

Unless contraindicated, the ADA recommends metformin monotherapy (MM) as the first-line pharmacologic agent for T2DM 
treatment. ${ }^{5}$ Clinicians may consider second-line therapies on the basis of efficacy, hypoglycemia risk, weight change, side effects, and cost. ${ }^{6}$ If MM treatment does not result in glycemic control at a maximal tolerated dose over 3-6 months, individuals may receive either treatment intensification on top of metformin or switch to another antihyperglycemic agent (AHA) if metformin is not tolerated. ${ }^{5}$

Secondary MM failure refers to loss of glycemic control after initial achievement of control on MM. Data assessing secondary MM failure are limited. In the double-blind, randomized clinical trial ADOPT (A Diabetes Outcome Progression), in 4360 patients with T2DM, the cumulative prevalence of MM failure after 5 years of follow-up was $21 \%$. This study defined MM failure as fasting plasma glucose level $>180 \mathrm{mg} / \mathrm{dL} .{ }^{7}$ Brown et al $^{8}$ assessed secondary MM failure (defined as hemoglobin A1c (HbA1c) $\geq 7.5 \%$ $(58 \mathrm{mmol} / \mathrm{mol}))$ using real-world data from patients in Kaiser Permanente Northwest (KPNW) Health Maintenance Organization (HMO) group; they found a mean secondary MM failure prevalence of $17 \%$ annually, and among those who failed the mean time to failure was 16.9 months. Nichols et at also examined secondary MM failure in the KPNW population and found that $20.5 \%$ of patients who achieved $\mathrm{HbA1c}<8 \%$ (64 mmol/ mol) within a year of MM reached an $\mathrm{HbA1c} \geq 8 \%$ (64 $\mathrm{mmol} / \mathrm{mol}$ ) within a mean of 21.6 months. These findings suggest that MM durability in the real world may be lower than that previously reported in the ADOPT trial. However, it is difficult to generalize the findings from a randomized clinical trial (ADOPT) and a single healthcare system (KPNW) to a broader US patient population.

This study aimed to quantify and describe secondary MM failure within 2 years of initiating MM among a cohort of US patients with T2DM from a large, real-world electronic medical record (EMR) database.

\section{RESEARCH DESIGN AND METHODS}

\section{Data source and study design}

We conducted a retrospective cohort study among patients with T2DM in the IQVIA Electronic Medical Record database (formerly GE Centricity database); this database comprised data for more than 30 million US patients collected from over 30000 healthcare providers across 49 states. The database includes deidentified information on patient demographics (age, gender, race, type of insurance coverage), comorbidities, prescription medications, laboratory assessments and orders, and diagnostic tests results. Exploratory analyses of the IQVIA EMR database demonstrated its ability to detect ambulatory medical conditions that aligned with the annual National Ambulatory Medical Care survey, a national survey of non-federal, office-based physicians administered by the US Centers for Disease Control and Prevention. ${ }^{10}$ Furthermore, the IQVIA EMR database allows for indepth analysis of patterns of related comorbidities associated with T2DM across different demographic groups. ${ }^{11}$

This study included adults with T2DM (International Classification of Diseases (ICD)-9 codes: 250.x0, 250.x2; ICD-10 codes: E11) who initiated MM during the index assessment period (January 1, 2012-June 30, 2016) and achieved glycemic control (defined as HbAlc $<7 \%$ (53 $\mathrm{mmol} / \mathrm{mol}$ )) (figure 1). The index date was defined as the date of the first $\mathrm{HbAlc}$ result $<7 \%(53 \mathrm{mmol} / \mathrm{mol})$ within 1-6 months following the initiation date of MM. Patients were also required to be at least 18 years of age by the index date and have continuous data availability through baseline and follow-up periods. Patients were

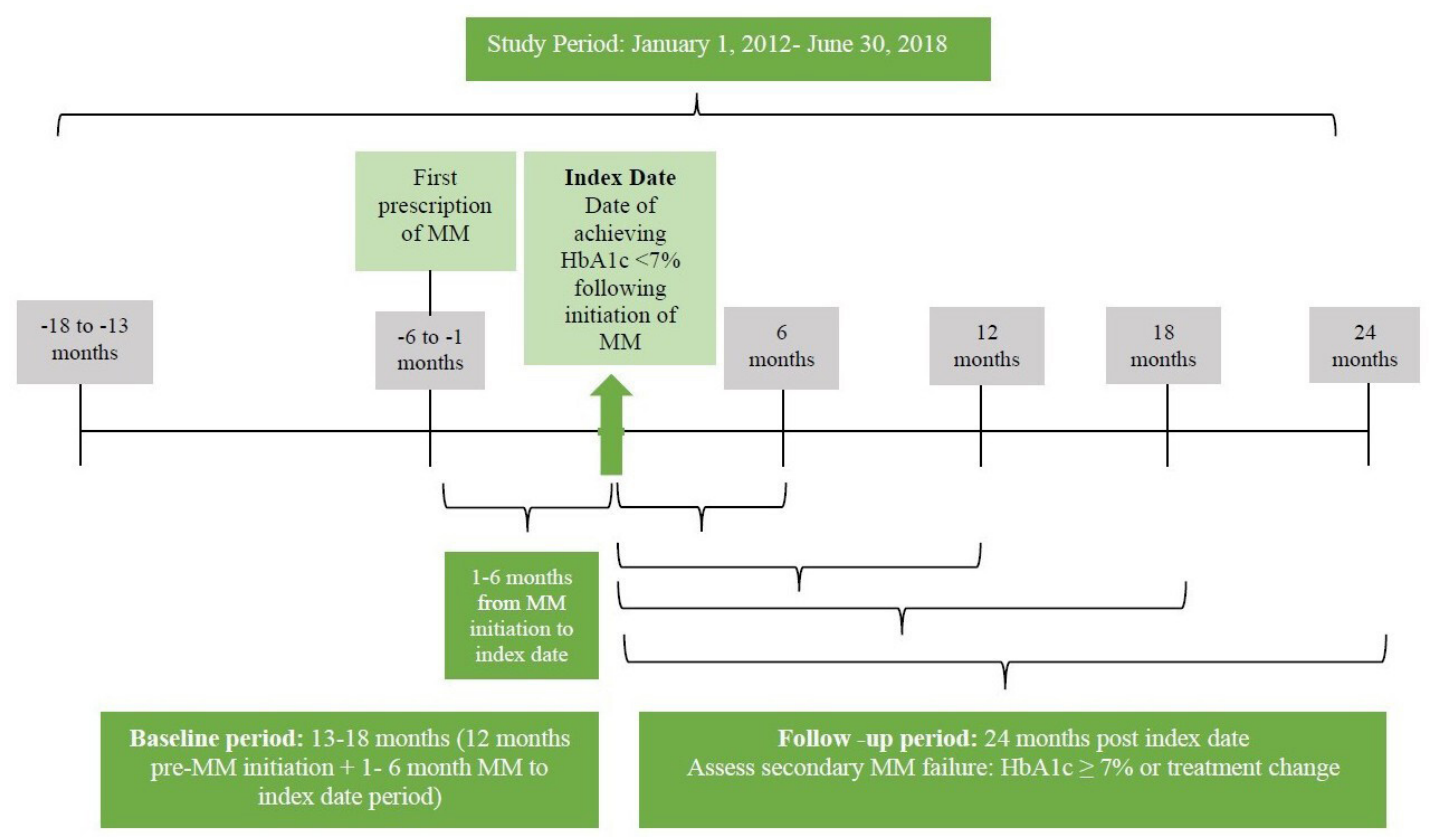

Figure 1 Study design. HbA1c, hemoglobin A1c; MM, metformin monotherapy. 
also required to have continuous MM prescriptions without a treatment gap of more than 90 days between the MM initiation date and the index date. Patients were also required to have an $\mathrm{HbAlc} \geq 6.5 \%$ (48 mmol/ $\mathrm{mol}$ ) in their history prior to MM initiation to further confirm T2DM diagnosis. Patients were excluded if they had a prescription for insulin or other AHAs during the 12 months prior to MM initiation or any time between the MM initiation date and the index date. Other exclusionary criteria consisted of diagnosis for type 1 diabetes, polycystic ovary syndrome, gestational diabetes, or other forms of secondary diabetes during the study period (online supplemental appendix 2 displays the cohort table and the diagnostic codes used).

\section{Outcomes}

The study evaluated secondary MM failure using two separate definitions: loss of glycemic control and/or treatment change. Loss of glycemic control was defined as an $\mathrm{HbAlc} \geq 7 \%$ (53 mmol/mol) after the index date within the observation period, as depicted in figure 1. Sensitivity analyses assessed loss of control as $\mathrm{HbAlc} \geq 7.5 \%$ $(58 \mathrm{mmol} / \mathrm{mol})$ and $\mathrm{HbAlc} \geq 8 \%(64 \mathrm{mmol} / \mathrm{mol})$ after the index date. Given the nature of this definition, only patients with an HbAlc available could be assessed for secondary MM failure by this definition. Treatment change was defined as the start of any other AHA prescription after the index date to either replace metformin or added to metformin for treatment intensification. All patients meeting the study inclusion/exclusion criteria, including those without available HbAlc measures, could be assessed for secondary MM failure by this definition. Secondary MM failure was estimated as part of an intent-to-treat analysis using the proportion of patients who experienced secondary MM failure by each definition separately at intervals of $0-6,0-12,0-18$, and $0-24$ months after the index date. For loss of glycemic control, proportions were based on all patients with HbAlc measures available in the relevant time periods, while for treatment change proportions were based on all patients in the study cohort (regardless of whether they had an HbA1c available). Sensitivity analyses were performed among (1) patients with index HbAlc $<7.5 \%(58 \mathrm{mmol} /$ mol) and (2) patients with two or more metformin prescriptions.

\section{Statistical analysis}

Descriptive statistics were reported for demographic and clinical characteristics as frequencies and percentages for categorical variables and as means and SD for continuous variables. The analysis generated separate multivariable logistic regression models for each definition of secondary MM failure to identify baseline characteristics associated with secondary MM failure at 24 months. Time until secondary MM failure was estimated with Kaplan-Meier (KM) curves for each definition of the outcome.

\section{RESULTS}

The database included 4775 patients with T2DM diagnoses who met all inclusion criteria. Table 1 summarizes the baseline and demographic characteristics of the cohort. More than half of the patients were younger than 65 years of age, with a mean age of 61.6 years (SD 11.9), and $53.4 \%$ were women. The majority of patients were white $(75.2 \%)$, followed by black (10.7\%), unknown race/ethnicity $(11.1 \%)$, and Asian $(2.3 \%)$. The largest proportion of patients resided in the South $(37.4 \%)$, while $28.6 \%$ resided in the Northeast. The mean baseline HbAlc (in the 12-month period prior to metformin initiation) was $7.3 \%$ (56 $\mathrm{mmol} / \mathrm{mol}$ ) (SD 1.1), while the median baseline HbAlc was $6.9 \%$ (IQR 6.7-7.4). The mean/median index HbA1c value (during the 1-6 months following metformin initiation) was $6.3 \%(45 \mathrm{mmol} / \mathrm{mol})$ (SD 0.4)/6.4 (IQR 6.1-6.6). Smoking was documented in $9.8 \%$ of the cohort. Microvascular complications included $7.6 \%$ and $3.8 \%$ of patients with nephropathy or neuropathy, respectively. Only $2.0 \%, 2.0 \%, 0.4 \%$, and $0.2 \%$ of patients had a history of peripheral arterial/vascular disease, stroke, myocardial infarction, or congestive heart failure, respectively. The mean Charlson Comorbidity Index (CCI) score was 1.1 (SD 1.7).

Loss of glycemic control was assessed among study participants who had HbAlc measures available in the follow-up period $(n=4591)$. Treatment change was computed using the entire study population $(\mathrm{N}=4775)$. Figure 2 summarizes the cumulative proportion of patients experiencing secondary MM failure as loss of glycemic control or treatment change over time. Among MM patients with an HbA1c measure available and an index $\mathrm{HbAlc}<7 \%$ (53 mmol $/ \mathrm{mol}), 10.8 \%$, $18.3 \%, 25.8 \%$, and $32.9 \%$ experienced loss of glycemic control (HbAlc $\geq 7 \%(53 \mathrm{mmol} / \mathrm{mol}))$ within 6,12 , 18 , and 24 months, respectively. Sensitivity analyses that evaluated loss of glycemic control as progression to $\mathrm{HbA} 1 \mathrm{c} \geq 7.5 \%$ ( $58 \mathrm{mmol} / \mathrm{mol})$ and $\geq 8 \%$ (64 mmol/ mol) showed trends similar to the analysis for progression to $\mathrm{HbAlc} \geq 7 \%$ (53 mmol $/ \mathrm{mol})$. More patients experienced secondary MM failure over time, yet the overall proportion was substantially smaller; $14.6 \%$ and $6.1 \%$ experienced secondary MM failure within 24 months when defined as a progression to HbAlc $\geq 7.5 \%(58 \mathrm{mmol} / \mathrm{mol})$ or $\geq 8 \%(64 \mathrm{mmol} / \mathrm{mol})$, respectively. Additional sensitivity analyses measuring secondary MM failure among patients with an index HbAlc $<7.5 \%(58 \mathrm{mmol} / \mathrm{mol})$ and in patients with two or more metformin prescriptions can be found in online supplemental appendix 1, and findings were in line with the results reported here.

Among patients classified as having secondary MM failure defined as treatment change, $7.0 \%, 11.2 \%, 15.3 \%$, and $19.2 \%$ changed therapy at $6,12,18$, and 24 months of follow-up, respectively. 
Table 1 Demographic and clinical characteristics of patients experiencing secondary MM failure

\begin{tabular}{|c|c|}
\hline Total & $\mathrm{N}=4775(100 \%)$ \\
\hline \multicolumn{2}{|l|}{ Age (years) } \\
\hline$<65$ & $2603(54.5)$ \\
\hline $65-75$ & $1330(27.8)$ \\
\hline $75+$ & $842(17.6)$ \\
\hline Median (Q1, Q3) & $63(53,71)$ \\
\hline Mean (SD) & $61.6(11.9)$ \\
\hline \multicolumn{2}{|l|}{ Gender } \\
\hline Female & $2549(53.4)$ \\
\hline Male & $2226(46.6)$ \\
\hline \multicolumn{2}{|l|}{ Race } \\
\hline White & $3589(75.2)$ \\
\hline Black & $510(10.7)$ \\
\hline Asian & $108(2.2)$ \\
\hline Indian (American) & $34(0.7)$ \\
\hline $\begin{array}{l}\text { Native Hawaiian or Other Pacific } \\
\text { Islander }\end{array}$ & $3(0.0)$ \\
\hline Unknown & $531(11.1)$ \\
\hline \multicolumn{2}{|l|}{ Region } \\
\hline South & $1785(37.4)$ \\
\hline Northeast & $1367(28.6)$ \\
\hline West & $911(19.1)$ \\
\hline Midwest & $711(14.9)$ \\
\hline Unknown/missing & $1(0.0)$ \\
\hline \multicolumn{2}{|l|}{$\mathrm{BMI}\left(\mathrm{kg} / \mathrm{m}^{2}\right)$} \\
\hline Mean (SD) & $33.8(6.9)$ \\
\hline Median (Q1, Q3) & $33.0(28.8,37.7)$ \\
\hline \multicolumn{2}{|l|}{ Baseline $\mathrm{HbA1c}$} \\
\hline Mean (SD) & $7.3^{\star}(1.1)$ \\
\hline Median (Q1, Q3) & $6.9 \dagger(6.7,7.4)$ \\
\hline \multicolumn{2}{|l|}{ Index HbA1c } \\
\hline Mean (SD) & $6.3 \neq(0.4)$ \\
\hline Median (Q1, Q3) & $6.4 \S(6.1,6.6)$ \\
\hline \multicolumn{2}{|l|}{ Behavioral attributes } \\
\hline Smoking & $470(9.8)$ \\
\hline \multicolumn{2}{|l|}{ Comorbidities } \\
\hline \multicolumn{2}{|l|}{ Microvascular complications } \\
\hline Nephropathy & $365(7.6)$ \\
\hline Neuropathy & $179(3.7)$ \\
\hline Retinopathy & $21(0.4)$ \\
\hline \multicolumn{2}{|l|}{ Macrovascular complications } \\
\hline Arrhythmia & $137(2.9)$ \\
\hline Stroke/transient ischemic attack & $98(2.0)$ \\
\hline $\begin{array}{l}\text { Peripheral arterial disease and } \\
\text { peripheral vascular disease }\end{array}$ & $94(2.0)$ \\
\hline Myocardial infarction & $33(0.7)$ \\
\hline
\end{tabular}

Continued

\begin{tabular}{ll} 
Table 1 Continued & $\mathbf{N}=\mathbf{4 7 7 5}(\mathbf{1 0 0 \% )}$ \\
\hline Total & $19(0.4)$ \\
\hline \multicolumn{1}{c}{ Angina } & $12(0.2)$ \\
Congestive heart failure & $6(0.1)$ \\
$\quad$ Revascularization & \\
Charlson Comorbidity Index score & \\
$\quad$ Mean (SD) & $1.1(1.7)$ \\
Median (Q1, Q3) & $0(0,2)$ \\
\hline
\end{tabular}

${ }^{*} \mathrm{HbA} 1 \mathrm{c} 7.3 \%(56 \mathrm{mmol} / \mathrm{mol})$

†HbA1c 6.9\% (52 mmol/mol).

łHbA1c $6.3 \%$ (45 mmol/mol).

$\S \mathrm{HbA} 1 \mathrm{c} 6.4 \%$ (46 mmol/mol).

$\mathrm{BMI}$, body mass index; HbA1c, hemoglobin A1c; MM, metformin monotherapy.

Figure 3 presents the ORs for factors associated with secondary MM failure from multivariable regression models. The analysis produced separate models for each definition: loss of glycemic control (HbAlc $\geq 7 \%$ $(53 \mathrm{mmol} / \mathrm{mol})$ ) and treatment change (figure 3). In the regression model for loss of glycemic control (figure 3), women were more likely to progress to HbAlc $\geq 7 \%$ ( $53 \mathrm{mmol} / \mathrm{mol}$ ) than men (OR $1.3,95 \%$ CI 1.1 to 1.5 ), whereas patients with higher baseline HbAlc (OR $=0.93,95 \%$ CI 0.88 to 0.98 ) and more comorbidities (ie, CCI) $(\mathrm{OR}=0.89,95 \%$ CI 0.86 to 0.93 ) were significantly less likely to experience MM failure. For the model that used treatment change as the outcome (figure 3), patients with higher CCI were significantly less likely to change treatment $(\mathrm{OR}=0.78$, $95 \%$ CI 0.75 to 0.82 ). No other characteristics were associated with treatment change.

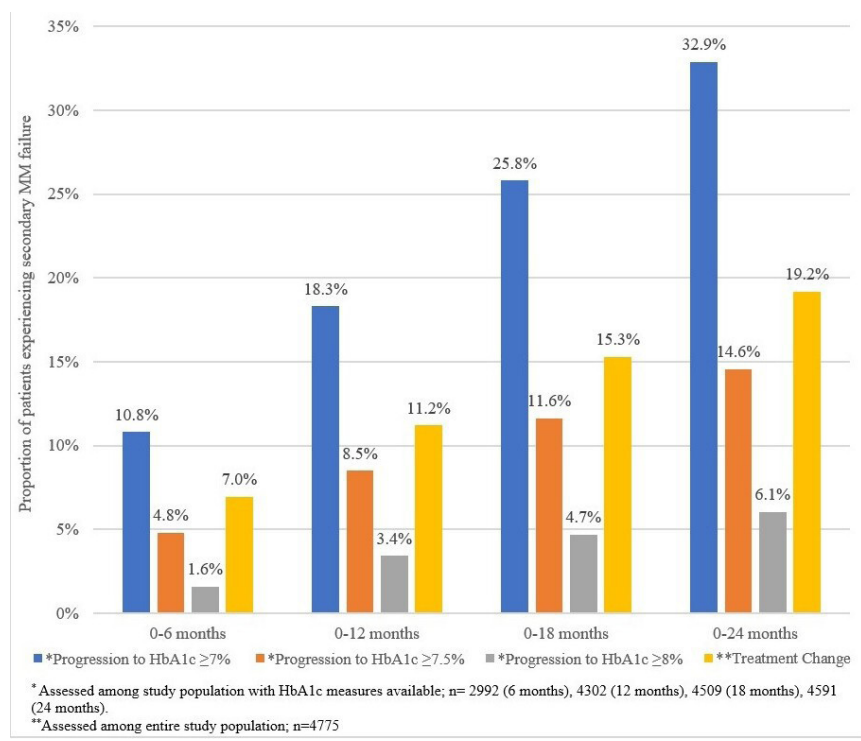

Figure 2 Proportion of patients with type 2 diabetes mellitus experiencing secondary MM failure, stratified by $\mathrm{HbA} 1 \mathrm{c}$ thresholds and treatment change. $\mathrm{HbA1c}$, hemoglobin A1c; MM, metformin monotherapy. 

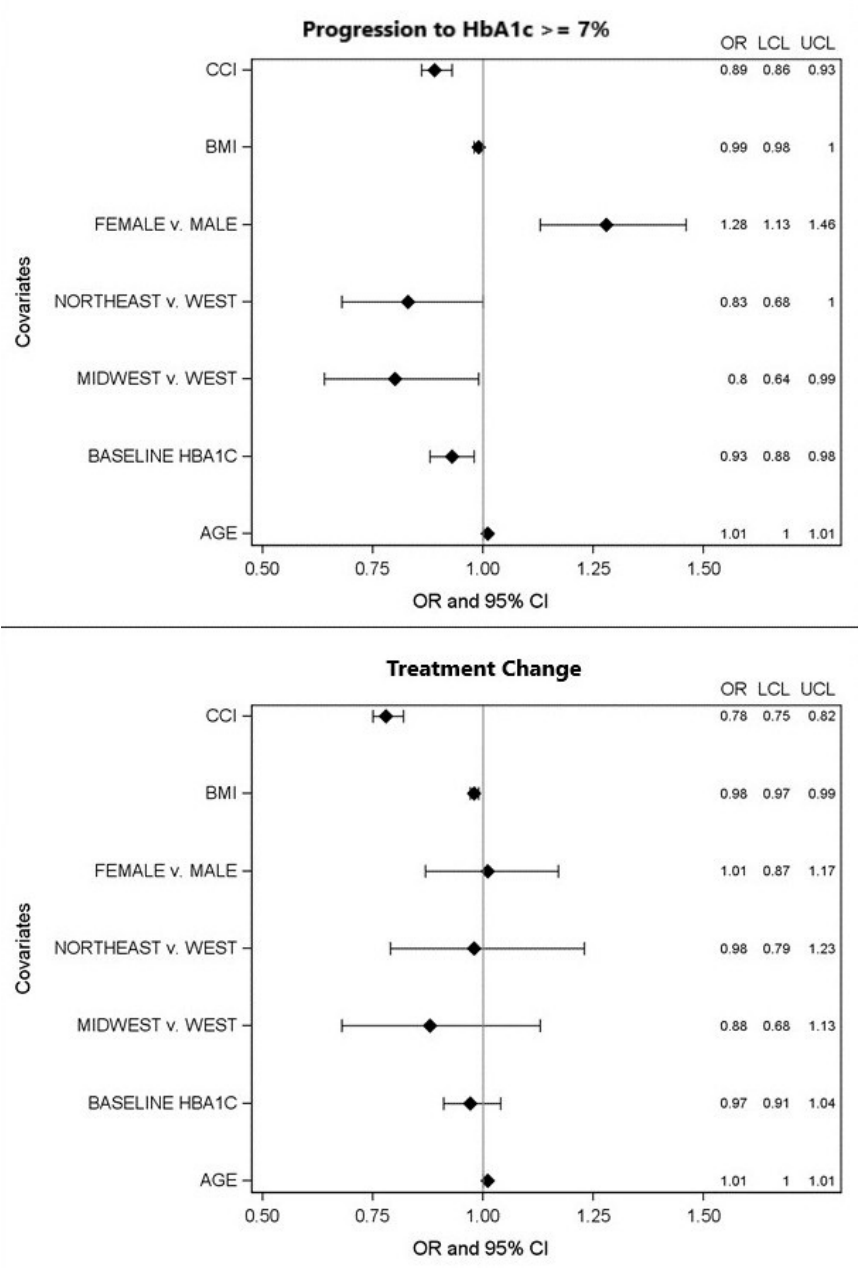

Figure 3 Odds Ratio (OR) for factors associated with secondary metformin monotherapy failure, defined as loss of glycemic control (progression to $\mathrm{HbA} 1 \mathrm{c} \geq 7 \%$ ) or treatment change. Variables in the multivariable logistic regression models included age, baseline $\mathrm{HbA1c}$, region (Midwest, Northeast, South, West), gender (female, male), $\mathrm{BMI}, \mathrm{CCl}$ score, retinopathy, nephropathy, neuropathy, acute myocardial infarction, angina, arrhythmia, revascularization, heart failure, peripheral arterial/vascular disease, stroke/ transient ischemic attack, alcohol, and smoking status. BMI, body mass index; $\mathrm{CCl}$, Charlson Comorbidity Index; $\mathrm{HbA1c}$, hemoglobin A1c; LCL, lower confidence limit; UCL, upper confidence limit.

Figure 4 depicts the KM curve for patients who progress to loss of glycemic control and treatment change. Around $2.7 \%$ of the patients experienced loss of glycemic control (HbA1c $\geq 7 \% \quad(53 \mathrm{mmol} /$ mol) ) within 100 days of initiating MM. At 12 months, $17.09 \%$ of the patients included in the final cohort experienced HbAlc levels $\geq 7 \%(53 \mathrm{mmol} / \mathrm{mol})$. At 24 months (730 days), $32.8 \%$ of the patients experienced loss of glycemic control (HbAlc $\geq 7 \%$ (53 $\mathrm{mmol} / \mathrm{mol})$ ). However, the percentage of patients undergoing treatment change at the end of follow-up period was comparatively lower than the percentage of patients experiencing loss of glycemic control.
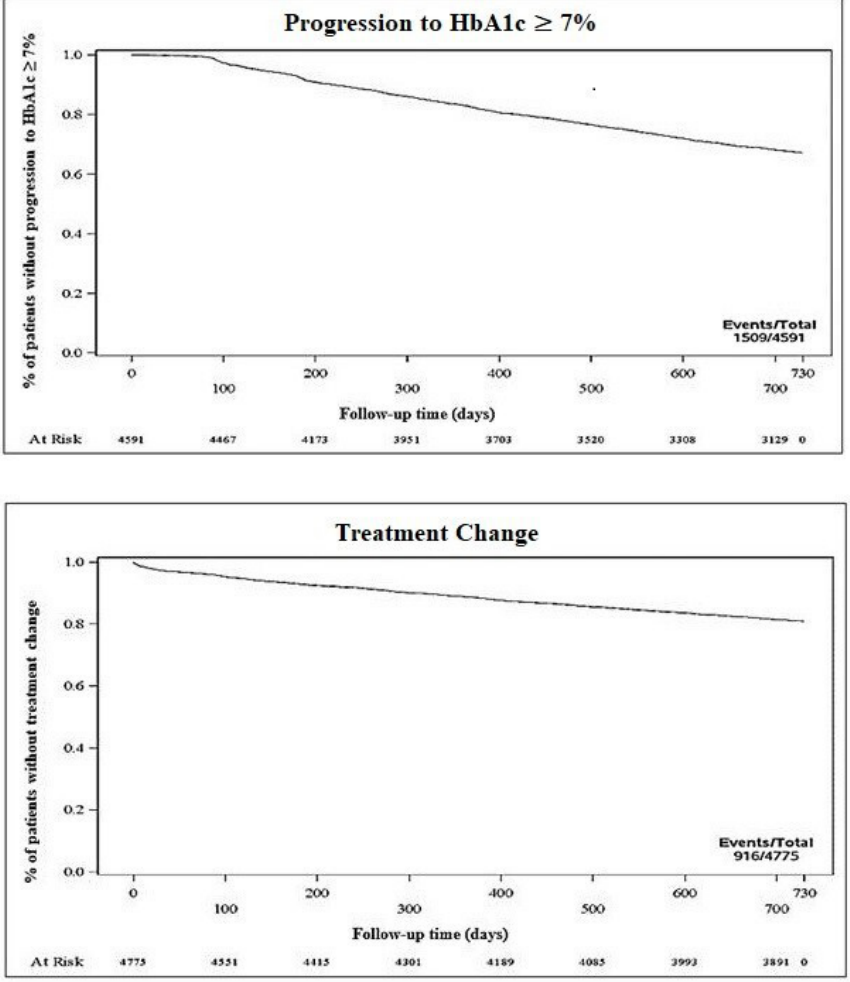

Figure 4 Kaplan-Meier curve for secondary metformin monotherapy failure by loss of glycemic control (progression to $\mathrm{HbA} 1 \mathrm{c} \geq 7 \%$ ) or treatment change. $\mathrm{HbA} 1 \mathrm{c}$, hemoglobin A1c.

Approximately $4 \%$ of the patients changed their treatment within 100 days of initiating MM and $20 \%$ of the patients underwent treatment change within 24 months of initiating MM.

\section{CONCLUSIONS}

This retrospective analysis of a cohort from a real-world EMR database assessed secondary MM failure, defined as loss of glycemic control (HbA1c $\geq 7 \%$ (53 mmol/ mol) ) and/or treatment change, among individuals with T2DM. Nearly one-third $(32.9 \%)$ of patients experienced secondary MM failure within 24 months by loss of glycemic control (HbAlc $\geq 7 \%$ (53 mmol/mol)). As secondary MM failure was redefined using higher thresholds for target HbAlc $(\geq 7.5 \% \quad(58 \mathrm{mmol} / \mathrm{mol})$ and $\geq 8.0 \%(64 \mathrm{mmol} / \mathrm{mol}))$, the prevalence of secondary MM failure was lower overall but consistently increased over time. Of the patients $19.2 \%$ experienced secondary MM failure by treatment change after 24 months. Factors associated with progression to $\mathrm{HbAlc} \geq 7 \%$ (53 mmol/ mol) were being a woman, having lower baseline HbAlc, and having lower CCI. Only lower CCI was found to be associated with treatment change.

As previously discussed, two real-world studies using KPNW patients reported an annual secondary MM failure rate of $17 \%,{ }^{8}$ loss of control (HbAlc $\geq 8 \%$ (64 $\mathrm{mmol} / \mathrm{mol})$ ) rate of $20.5 \%$, and treatment intensification rate of $25.9 \%$ over a mean time of 21.6 months 
and 27.5 months, respectively. ${ }^{9}$ The findings of this study are consistent with the Kaiser real-world studies on rates of loss of glycemic control, but in a larger US population. Further, in Kaiser's analysis, $5 \%, 9 \%$, and $50 \%$ of patients progressed to $\mathrm{HbA} 1 \mathrm{c} \geq 8 \%(64 \mathrm{mmol} /$ mol), stratified by baseline HbAlc of $<6 \%$ ( $42 \mathrm{mmol} /$ $\mathrm{mol}), 6 \%-6.9 \%(42-52 \mathrm{mmol} / \mathrm{mol})$, and $7 \%-7.9 \%$ (53-63 mmol/mol), respectively. ${ }^{9}$ While the present study did not stratify loss of glycemic control by baseline $\mathrm{HbA} 1 \mathrm{c}$, it did find $6.1 \%$ of patients progressed to an $\mathrm{HbAlc} \geq 8 \%(64 \mathrm{mmol} / \mathrm{mol})$ at 24 months (sensitivity analysis). For treatment change, the KM curves for the Kaiser cohort showed that $~ 5 \%-35 \%$ of patients changed therapies, stratified by lowest achieved HbAlc in the previous 12 months $(<6 \%(42 \mathrm{mmol} /$ $\mathrm{mol}$ ), $6 \%-6.9 \%$ (42-52 $\mathrm{mmol} / \mathrm{mol}), 7 \%-7.9 \%$ (53-63 $\mathrm{mmol} / \mathrm{mol})){ }^{9}$ The findings of the present study fall about halfway between this range (19\%). Using large, pharmacy claims databases based on a US population, Riedel et $a l^{12}$ reported a secondary MM failure (HbAlc $\geq 7 \%(53 \mathrm{mmol} / \mathrm{mol}))$ of $35.5 \%$ over 4 years, although the present study found that a similar proportion of patients failed by the same definition within 2 years. The ADA guidelines recommend performing HbAlc tests at least twice a year in patients who are meeting treatment goals. ${ }^{13}$ Regular monitoring of HbAlc would allow for timely treatment adjustments and, if needed, intensification. The present study confirms the findings of the previous studies out of KPNW on a national level and shows that a substantial proportion of patients who achieve glycemic targets on MM go on to lose glycemic control or change therapy in a relatively short period of time. This underscores the importance of the ADA's recommendation for biannual glycemic testing in patients under glycemic control.

Although these findings share considerable similarity with prior research, there are some key differences. First, patients with greater comorbidity burden or higher HbA1c at baseline were less likely to experience secondary MM failure, defined either based on HbAlc level or treatment intensification at 24 months. This is also contrary to previous literature suggesting that the impact of comorbidity on glycemic control is insignificant. ${ }^{14} 15$ It is possible these findings could reflect closer medical management or better adherence to $\mathrm{MM}$ in a population with more comorbid conditions, but it is impossible to fully examine the reasons behind this finding given the nature of a database study. Furthermore, Nichols et $a l^{9}$ found that compared with having an HbA1c $<7 \%$ (53 $\mathrm{mmol} / \mathrm{mol}$ ) at metformin initiation, an $\mathrm{HbAlc}>7 \%$ (53 mmol/mol) had 1.30-3.26 times greater risk of secondary MM failure by treatment change or loss of control. Interestingly, this study found the opposite to be true for the relationship between baseline HbAlc, or HbA1c prior to MM initiation, and secondary MM failure by loss of glycemic control and found no association between baseline HbAlc and secondary MM failure by treatment change. Second, Choe $e t a l^{16}$ had reported sex-based differences in glycemic control and recommended sex-specific approach for glycemic control management. In our study, women displayed significantly higher likelihood of secondary MM failure by loss of control ( $\mathrm{HbA} 1 \mathrm{c} \geq 7 \%(53 \mathrm{mmol} / \mathrm{mol}))$ $(\mathrm{OR}=1.28)$. This association when measured as treatment intensification, although significant, was modest in comparison.

The current study has several limitations due to its retrospective, observational design. EMR data record information on prescribed medications and not dispensed medication or medication use; therefore, there is no way to confirm that patients were truly on MM. The analysis attempted to address this limitation through a sensitivity analysis, namely examining the primary objective in a subset of patients with two or more consecutive metformin prescriptions, and found similar results (online supplemental appendix 1). The EMR data also do not capture the reasons behind switching therapy or treatment intensification. Using treatment intensification as a proxy for secondary MM failure may introduce outcome misclassification bias; treatment change may be unrelated to secondary MM failure, and instead due to reasons including but not limited to adverse reactions to metformin, a lower individualized $\mathrm{HbAlc}$ goal, or a desire to change treatment due to non-glycemic benefits of another treatment (ie, weight loss, cardiovascular, and/ or diabetic kidney disease benefits). However, this definition was included as a proxy measure for secondary MM failure due to more limited capture of $\mathrm{HbAlc}$ measures in EMR databases. Furthermore, although the ADA considers a target of $\mathrm{HbAlc}$ level $<7 \%(53 \mathrm{mmol} / \mathrm{mol})$ as optimal glycemic control for most patients, ${ }^{2}$ a higher glycemic target may be appropriate for some patients and thus they may have been inappropriately classified as having failed treatment. We attempted to address this limitation by performing sensitivity analyses redefining loss of glycemic control as $\mathrm{HbAlc} \geq 7.5 \%(58 \mathrm{mmol} / \mathrm{mol})$ and $\geq 8 \%(64 \mathrm{mmol} / \mathrm{mol})$. Intent-to-treat approach used to assess the HbAlc measurements may be susceptible to treatment-related attrition or exposure misclassification or both, namely non-adherence, switching, or augmentation. Finally, the HbA1c measurements were not always available for each follow-up time, thereby reducing the precision of estimates. The analysis, however, used relatively short intervals of $6,12,18$, and 24 months of follow-up in order to minimize the bias. Lastly, the IQVIA EMR database is representative of 30 million US patients receiving ambulatory care from 30000 healthcare providers across 49 states, and thus represents a larger, more diverse pool of patients with T2DM than previous analyses on secondary MM failure. ${ }^{7-9}$ Nevertheless, it may not be generalizable to the entire US T2DM population.

In conclusion, this retrospective cohort study of real-world patients with type 2 diabetes documented that the likelihood of secondary MM failure increases over time regardless of HbAlc values used to define it. 
Approximately one-third of the patients initiating MM progressed to $\mathrm{HbAlc} \geq 7 \%(53 \mathrm{mmol} / \mathrm{mol})$ and $19 \%$ either switched or intensified MM within 24 months. It is important that patients on MM receive glycemic monitoring at least every 6 months, as recommended by the ADA, to ensure loss of glycemic control is readily identified and proper therapeutic adjustments are made in a timely manner. Further studies assessing whether initial metformin combination therapy would result in more durable glycemic control would be valuable.

Acknowledgements The authors acknowledge Niranjan Kathe and Irene Doherty of Complete HEOR Solutions for their technical and medical writing assistance with this manuscript.

Contributors TW, KI, SR, LY, and LB were involved in the conception and design of the study. TW and TG were involved in data analysis. All authors were involved in drafting of the paper and revising it critically for intellectual content. All authors approved of the final version of this manuscript and agree to be accountable for all aspects of the work.

Funding Funding for this research was provided by Merck Sharp \& Dohme, a subsidiary of Merck \& Co, Kenilworth, New Jersey, USA.

Competing interests TW, LY, and SR are employees of Merck Sharp \& Dohme, a subsidiary of Merck \& Co., Inc., Kenilworth, New Jersey, USA. KI was an employee of Merck Sharp \& Dohme, a subsidiary of Merck \& Co., Inc. at the time of study completion. LB is an employee of Ochsner Medical Center. TG was an employee of Complete HEOR Solutions, North Wales, Pennsylvania, USA, which was contracted to complete the study analysis on behalf of Merck \& Co., Inc.

Patient consent for publication Not required.

Provenance and peer review Not commissioned; externally peer reviewed.

Data availability statement All data relevant to the study are included in the article or uploaded as supplementary information. Merck licensed the EMR data used in this study from IQVIA. Under its agreement with IQVIA, Merck does not have the permission to release the data to or share the data with any third party without explicit contractual consent between the third party and IQVIA. The study protocol contains the specifications of the database and details of patient selection. The study protocol is available upon request.

Supplemental material This content has been supplied by the author(s). It has not been vetted by BMJ Publishing Group Limited (BMJ) and may not have been peer-reviewed. Any opinions or recommendations discussed are solely those of the author(s) and are not endorsed by BMJ. BMJ disclaims all liability and responsibility arising from any reliance placed on the content. Where the content includes any translated material, BMJ does not warrant the accuracy and reliability of the translations (including but not limited to local regulations, clinical guidelines, terminology, drug names and drug dosages), and is not responsible for any error and/or omissions arising from translation and adaptation or otherwise.

Open access This is an open access article distributed in accordance with the Creative Commons Attribution Non Commercial (CC BY-NC 4.0) license, which permits others to distribute, remix, adapt, build upon this work non-commercially, and license their derivative works on different terms, provided the original work is properly cited, appropriate credit is given, any changes made indicated, and the use is non-commercial. See: http://creativecommons.org/licenses/by-nc/4.0/.

ORCID iDs

Tracey Weiss http://orcid.org/0000-0001-6524-2412

Swapnil Rajpathak http://orcid.org/0000-0002-6052-2949

\section{REFERENCES}

1 Centers for Disease Control and Prevention. Centers for disease control and prevention. National diabetes statistics report. Atlanta, GA: US Department of Health and Human Services, 2020.

2 American Diabetes Association. 6. Glycemic Targets: Standards of Medical Care in Diabetes-2020. Diabetes Care 2020;43:S66-76.

3 Khunti S, Davies MJ, Khunti K. Clinical inertia in the management of type 2 diabetes mellitus: a focused literature review. $\mathrm{Br} J$ Diabetes 2015;15:65-95.

4 Wallace TM, Matthews DR. Poor glycaemic control in type 2 diabetes: a conspiracy of disease, suboptimal therapy and attitude. QJM 2000;93:369-74.

5 American Diabetes Association. 9. Pharmacologic Approaches to Glycemic Treatment: Standards of Medical Care in Diabetes-2020. Diabetes Care 2020;43:S98-110.

6 Palmer SC, Strippoli GFM. Metformin as first-line treatment for type 2 diabetes. Lancet 2018;392:120.

7 Kahn SE, Haffner SM, Heise MA, et al. Glycemic durability of rosiglitazone, metformin, or glyburide monotherapy. N Engl J Med 2006;355:2427-43.

8 Brown JB, Conner C, Nichols GA. Secondary failure of metformin monotherapy in clinical practice. Diabetes Care 2010;33:501-6.

9 Nichols GA, Alexander CM, Girman CJ, et al. Treatment escalation and rise in $\mathrm{HbA} 1 \mathrm{c}$ following successful initial metformin therapy. Diabetes Care 2006;29:504-9.

10 Crawford AG, Cote C, Couto J, et al. Comparison of GE Centricity electronic medical record database and national ambulatory medical care survey findings on the prevalence of major conditions in the United States. Popul Health Manag 2010;13:139-50.

11 Crawford AG, Cote C, Couto J, et al. Prevalence of obesity, type II diabetes mellitus, hyperlipidemia, and hypertension in the United States: findings from the GE Centricity electronic medical record database. Popul Health Manag 2010;13:151-61.

12 Riedel AA, Heien $\mathrm{H}$, Wogen J, et al. Loss of glycemic control in patients with type 2 diabetes mellitus who were receiving initial metformin, sulfonylurea, or thiazolidinedione monotherapy. Pharmacotherapy 2007;27:1102-10.

13 American Diabetes Association. 6. Glycemic Targets: Standards of Medical Care in Diabetes-2019. Diabetes Care 2019;42:S61-70.

14 El-Kebbi IM, Ziemer DC, Cook CB, et al. Comorbidity and glycemic control in patients with type 2 diabetes. Arch Intern Med 2001;161:1295-300.

15 Luijks $\mathrm{H}$, Biermans $\mathrm{M}$, Bor $\mathrm{H}$, et al. The effect of comorbidity on glycemic control and systolic blood pressure in type 2 diabetes: a cohort study with 5 year follow-up in primary care. PLoS One 2015;10:e0138662.

16 Choe S-A, Kim JY, Ro YS, et al. Women are less likely than men to achieve optimal glycemic control after 1 year of treatment: a multi-level analysis of a Korean primary care cohort. PLoS One 2018;13:e0196719. 